\title{
EXCISION OF A LARGE ORBITAL DERMOID CYST*
}

BY

\author{
MILROY PAUL \\ University of Ceylon
}

EVERY operation for the excision of an orbital dermoid cyst extending deeply into the orbit is fraught with danger of operative trauma to the contents of the orbit. The results of such operations are worthy of record as they assist a correct assessment of the operative risk.

\section{Case Report}

T. J., a male Ceylon Tamil aged 15, was admitted to the General Hospital, Colombo, on April 29, 1952, on account of a tumour growing within the right orbit. The tumour had been noted when he was one year old and had been growing steadily larger, the sight of the right eye having been impaired for the last 7 years.

Examination.-A soft, fluctuant, oval mass bulged forwards under the right upper eyelid and occupied the space between the upper orbital rim and the eyeball (Fig. 1). The eyeball was pushed downwards $\frac{3}{4}$ " below the level of the left eyeball, and the right orbit was wider than the left. There was no proptosis. The movements of the right eyeball were not impaired and there was no squint. On eversion of the upper eyelid, an oval mass could be seen bulging the upper conjunctival fornix. The tumour was not adherent to the eyelid or conjunctiva. No pulsations were detected on palpation.

Diagnosis.-The long duration of the tumour classed it as a non-malignant growth and its round, smooth shape and fluctuant consistency suggested that it might be an orbital dermoid. The absence of pulsation in the tumour, and the fact that a radiograph showed no abnormal aperture between the orbit and cranial cavity suggested that the cyst was not a meningocoele. The widening of the right orbit is seen in Fig. 2.

The steady enlargement of the tumour, the facial distortion produced by displacement of the eyeball downwards, and the deterioration in the sight of the right eye made removal of the tumour desirable. Its position made damage to the levator palpebrae

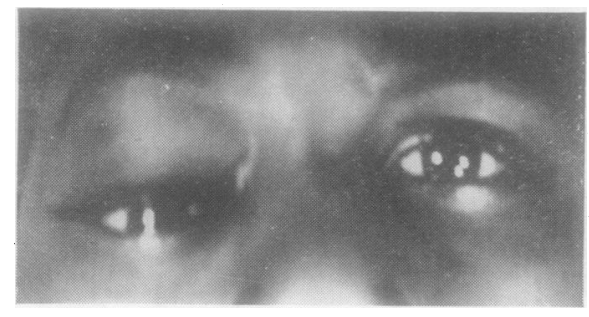

FIG. 1.-Before operation.

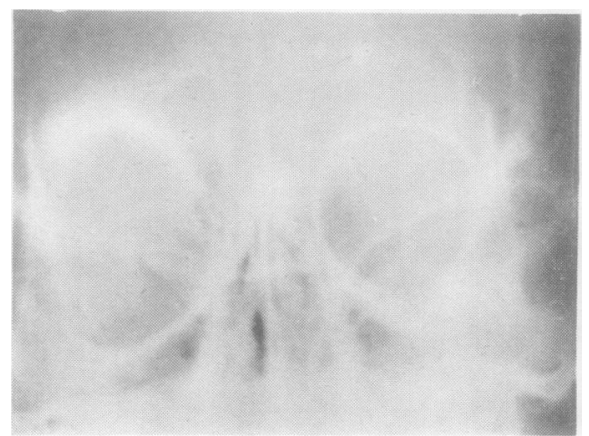

FIG. 2. $-X$ ray showing distortion of orbital cavity.

* Received for publication July 22, 1952. 


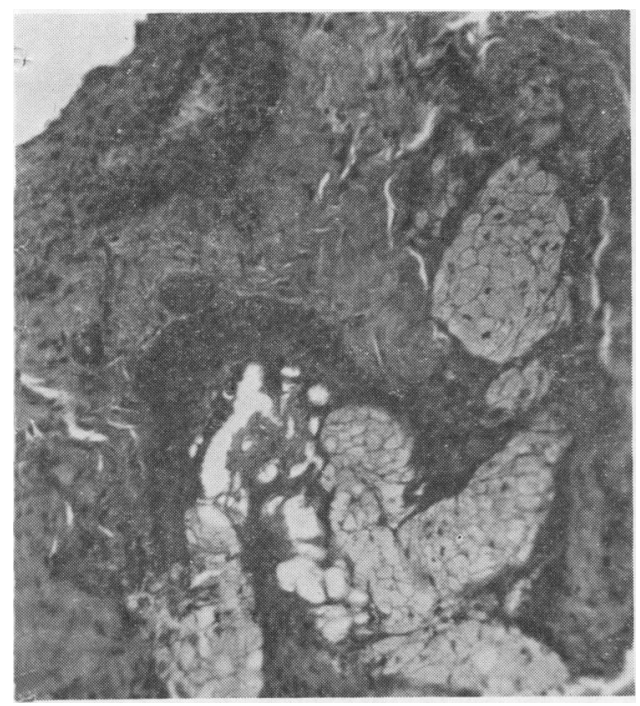

Fig. 3.-Photomicrograph of cyst wall showing skin and sebaceous glands. It was opened during the dissection, and cheesy debris with fine white downy hairs extruded from its lumen, but this partial emptying of the cyst greatly facilitated the dissection. A probe introduced into its lumen showed it to be sausage-shaped and to extend $40 \mathrm{~mm}$. back to the apex of the orbit. The cyst wall was carefully drawn forwards and it was eventually dissected right out of its bed (Fig. 3). There was no appreciable bleeding. No sutures were placed in the wound in the conjunctival fornix.

Results.-The next day the upper eyelid was swollen, and could not be raised; 4 days later the swelling was less and the lid could be raised sufficiently to open the eye. The movements of the eyeball were unimpaired. The patient made a good recovery (Fig. 4), and when he left hospital on May 16, 1952, could open the right eye readily, but he could not retract the upper eyelid while looking upwards, and when he closed the eye the lower lid moved upwards to the upper lid. He was however well satisfied to be rid of the cyst, and to be able to use the eye much more efficiently than before.

\section{BIBLIOGRAPHY}

Pfeiffer, R. L., and Nicholl, R. J. (1948). Trans. Amer. ophthal. Soc., 46, 218. ReEse, A. B. (1951). "Tumors of the Eye ", p. 490 . Cassell, London. 